\title{
Evaluation of the comprehensive benefits of vegetation restoration of rare- earth tails in Xunwu County
}

\author{
Lu Xianghui ${ }^{1,2, a}$, Tang Anhua ${ }^{2, b}$ and Jianmin Zhao ${ }^{2, \mathrm{c}}$ \\ ${ }^{1}$ Key Laboratory of Soil Erosion and Prevention, Nanchang Jiangxi Province, Nanchang 330029, \\ China) \\ ${ }^{2}$ College of Water and Ecology engineering, Nanchang Institute of Technology, Nanchang 330099, \\ China; \\ axianghuilu@nit.edu.cn, ${ }^{\mathrm{b}}$ anhuatang@yahoo.com, ${ }^{\circ}$ iianming1980@tom.com
}

\begin{abstract}
Keywords: Eucalyptus; rare-earth tails; analytic hierarchy process; evaluation
Abstract: Rare earth elements (REE) are important mineral resource in China, especially in Jiangxi province, Inner Mongolia. There is abundance of tailings in the REE mining area, which is harmful for the ecosystem and environment. Eucalyptus is one kind of tree which has often been used in the in ecological restoration for the tailings field of the REE mining area in Jiangxi province. Taking REE mining area of Xunwu County in the south of Jiangxi province as a study region, the comprehensive benefits of ecosystem restoration in tailings field with eucalyptus was examined this paper for evaluating the achievements and defects of ecosystem restoration. Xunwu County is not only one of the most important REE mining areas in China, but also the first county in the head streams of Dongjiang river, one of three branches in Pearl river basin. This river's inflow is the water source for the domestic and industrial needs of Hong Kong, Shenzhen, Guangzhou and other cities. After detailed surveys and evaluations of experts, 26 main indexes were determined for appraising the comprehensive impacts of vegetation restoration with eucalyptus on the ecological environment in tailings field of the REE mining area in Xunwu County. Then the model for evaluating comprehensive benefits of vegetation restoration with eucalyptus was put forward for with the analytic hierarchy process (AHP) method and fuzzy mathematics theory. Finally, according to the different assessments by several experts (two persons), local officials (four persons), scientists (three persons), farmers (eight persons) and entrepreneurs in REE industry (three persons), who were randomly selected, the comprehensive benefit of eucalyptus in tailings fields of the REE mining area was evaluated with the above model. It was generally shown in this research that during the ecosystem restoration with eucalyptus in tailings field of REE minerals, the ecological benefits and economic benefits were both general. The social benefits were good, and the comprehensive benefits were general. On the other hand, the overview assessment showed that, generally speaking, the comprehensive benefits of eucalyptus were thought as excellent, good, general, poor and bad by 17\%, 28\%, 30\%, 21\% and 4\% of above surveyed in research, respectively. It was suggested in this article that the eucalyptus was useful for ecological restoration in the tailings field of REE minerals in Xunwu County, Jiangxi province. The social benefits of ecosystem restoration with eucalyptus in tailings field were good, which is higher than the ecological benefits and economic benefits. So there was something to be done to improve the ecological and economic benefits of ecological restoration with eucalyptus in the tailings field of REE minerals. The reasons behind the lacking of ecological and economic benefits in ecological restoration with eucalyptus were lacking of biodiversity, and a shortage of soil water in the tailings field of REE minerals. There should be some research and other things to deal with above problems.
\end{abstract}

\section{Introduction}

The mineral wastes residues produced from rare earth mining is defined as rare earth tailings, which occupy a large quantity of land resources and leave them with loosen texture. If these issues are not handled properly, the resultant soil erosion will severely influence our ecological environment. It is 
known that in the South of the Five Ridges of China, on one hand is an important place of origin for rare earth, and on the other hand is a significant water source in the Yangtze River and Pearl River Basin. In order to protect the ecological environment and prevent soil erosion and water pollution, special attention must be paid to the remediation of land covered by rare earth tailings. One typical example is the rare earth ore of Xunwu County located at the south mountains of Jiangxi Province, which has rich reserves of rare earth resources. Since 1970s, rare earth mining has contributed the local economic development. However, limited to the laggard mining techniques, a huge amount of tailings was randomly stacked near the rare earth core without proper or timely treatment. They formed an artificial "crisscross gullies, red desert" landscape [1], which not only occupied abundant farmland, destroyed vegetation, and caused serious soil erosion, but also resulted in groundwater pollution and geological hazards. Moreover, Xunwu County sits at Dongjiang River source, which is the main water source for Guangdong City and Hong Kong residents. Large areas of accumulated rare earth tailings also incurred a potential impact on the water quality of Dongjiang River source [2]. Observing this phenomenon, Xunwu County government executed vegetation recovery to counter rare earth tailings. In the meantime, they actively cooperated with scientific research institutes, and screened out the fast rare earth zone vegetation recovery method using Eucalyptus Robusta Smith combined with mixed grass seeds through plenty of introduction practices. The vegetation coverage of the rare earth zone has been greatly improved after several years' treatment. Currently, the eucalyptus planting area accounts for more than $60 \%$ of the rare earth zone in Xunwu County. Artificial eucalyptus forest has greatly promoted the vegetation coverage of bare rare earth area, but its influence on the ecological environment has always been debatable $[3,4,5]$. Whether eucalyptuses can enhance the ecological environment of rare earth tailing affected area has not been clearly reported yet. Therefore, questions like whether the measures of using eucalyptuses to solve the rare earth tailing problem are reasonable, whether large-scale cultivation of eucalyptus artificial forest in the rare earth tailing treatment is favorable, and how the ecological and social benefits shall be evaluated scientifically, all demand a clear explanation from the local government. This paper took the rare earth tailing management area in Wenfeng Village, Xunwu County as the research object, adopted the analytic hierarchy process (AHP) model, and comprehensively evaluated the ecological, social and economic benefits of using eucalyptuses to solve the rare earth tailing problem. This research results will provide a theoretical basis for the pros and cons of the existing rehabilitation measures, and offer guidance and strategies to the management prospects of these methods. So the conclusion drawn in the paper will play a positive role in the soil and water conservation, and water source protection of Dongjiang river source, as well as the sustainable use of rare earth resources.

\section{Material and Methods}

Research area survey. The research area locates in Wenfeng Village, Xunwu County, Ganzhou City, Jiangxi Province (Fig.1). Xunwu County sits at the junction of Jiangxi Province and Fujian Province, which is the origin of Dongjiang River in Pearl River Basin with rich rare earth resources. Wenfeng Village sits in the southeast of Xunwu County, which the middle of Xunwu River passes through as branch of the Dongjiang River of Pearl River System. It is also the main rare earth production area in Xunwu County. Since mining started in the mid-1970s, the rare earth tailings left and bare bedrocks have collaboratively formed a bare land caused by rare earth mining, which is known as the "Southern Desert" by reason of barren vegetation. The total area of the research zone is $81.66 \mathrm{~km}^{2}$ with a soil erosion area of $58.80 \mathrm{~km}^{2}$, which accounts for $72 \%$ of the total area. Accumulated rare earth tailings present an irregular shape with big topographical fluctuations. The relative elevation of these tailings can reach about $150 \mathrm{~m}$, and the area with slopes above $15^{\circ}$ accounts for $66.39 \%$ of the total mining area. In addition, the studied area resides in subtropical humid climate zones with abundant rainfall. The average annual precipitation of this area over the years is $1,639.1 \mathrm{~mm}$, of which approximately $50 \%$ 
occurs from April to June. Most of the rainfall appears as storms. Lastly, the climate of this area is mild with an average annual temperature over the years to be $17.9^{\circ} \mathrm{C}$.

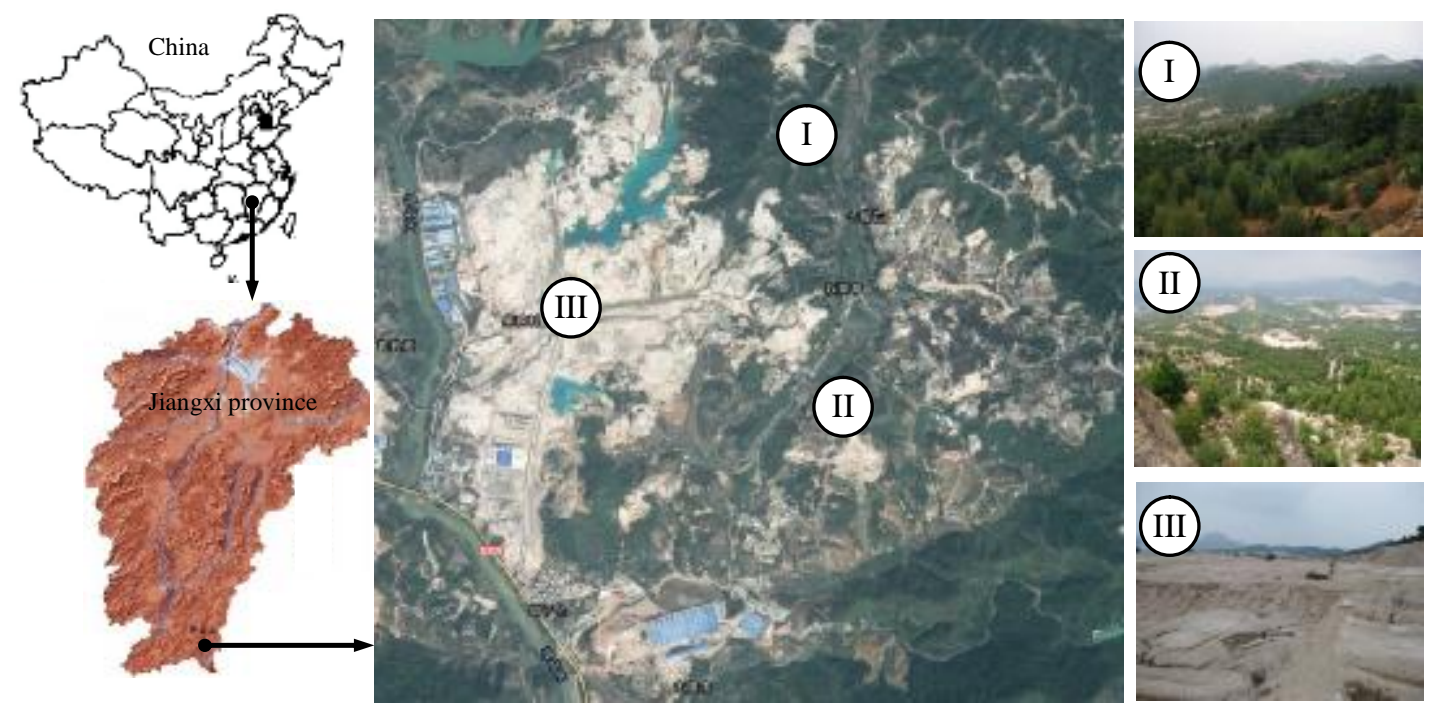

Fig. 1. Location of the Xunwu county rare earth tailing Eucalyptus plantation restoration project area. There is located south of Jiangxi province, China.

There plots were selected to test change of soil and plant characteristics after the restoration project.

According to the discussion with relevant departments and field investigation, the studied area was all exposed rare earth tailings prior to the implementation of rehabilitation measures, without any vegetation and under poor natural conditions. In 2008, the Soil and Water Conservation Bureau of Xunwu County started the govern of the rare earth tailings in the research region, and cultivation of eucalyptuses and mixed grass seeds. Until 2014, a mass of artificial eucalyptus forest has been planted and the vegetation coverage percentage has gone beyond $60 \%$. By then the initial success turned up.

Methods. Evaluation of the impact of eucalyptuses' growth on the ecological environment indicates fuzziness, so fuzzy mathematical method was deployed in this study to determine the weight of each evaluation index. However, weight coefficients were normally derived from methods designated by experts [6], so inevitably affected by subjective factors, which biased the evaluation results. Another method called AHP can carry out quantitative analysis for non-quantitative events [7], which ensured both a scientific qualitative representation and an accurate quantitative analysis. This method achieved index unification in qualitative and quantitative evaluations and avoided the deviation of the evaluation owing to subjective factors.

The main objective of this paper is to establish an evaluation assessment system for the restoring outcome of planting eucalyptuses in the studied area. Experts were invited to score the restoring outcome according to the indices. There will be five grades given from experts' judgement i.e. Excellent, Good, Average, Poor, and Inferior. Finally, an AHP and fuzzy mathematics combined comprehensive evaluation model was employed to evaluate the comprehensive benefit of eucalyptuses working on rare earth tailings.

\section{Results and Analysis}

Establishment of clustering factor comprehensive assessment index system. The comprehensive restoration benefit of eucalyptuses for the plantation of areas covered by rare earth tailings basically includes ecological, social and economic benefits. Each of these benefits has its own evaluation index. 
In order to accurately assess these benefits, authors of this paper conducted detailed investigation and paid site visits to rare earth tailings covered areas located in Wenfeng Village, Xunwu County. They also compared the current status of rare earth tailing rectification with the original objective of setting up the artificial eucalyptus forest. Finally, based on the acquired data, the paper sorted all the evaluation factors, and built a two-layer hierarchical clustering factor index system (see Table 1).

Determination of weights of clustering factors. Based on the established clustering factor index system for comprehensive benefit assessment, people (including 2 experts, 4 government officers, 3 scholars, 8 farmers and 3 rare earth ore owners) were invited to score the restoring outcome according to various hierarchical clustering factors, and graded the outcome from Excellent, Good, Average, Poor to Inferior. Finally, the researchers of the paper normalized all the scoring results of various evaluation indexes (see Table 1).

Table 1. Comprehensive benefit evaluation index system and score of eucalyptuses' restoration of rare earth tailings in Xunwu County (twenty people in total)

\begin{tabular}{|c|c|c|c|c|c|c|}
\hline \multirow{2}{*}{ First layer indices } & \multirow{2}{*}{ Second layer indices } & \multicolumn{5}{|c|}{ Comment set } \\
\hline & & Excellent $\left(V_{1}\right)$ & Good $\left(V_{2}\right)$ & Average $\left(V_{3}\right)$ & Poor $\left(V_{4}\right)$ & Inferior $\left(V_{5}\right)$ \\
\hline \multirow{10}{*}{ Ecological benefits $\left(A_{1}\right)$} & Water conservation $\left(B_{1}\right)$ & 0.10 & 0.10 & 0.35 & 0.40 & 0.05 \\
\hline & Erosion prevention $\left(\mathrm{B}_{2}\right)$ & 0.10 & 0.10 & 0.40 & 0.40 & 0.00 \\
\hline & Soil improvement $\left(B_{3}\right)$ & 0.35 & 0.45 & 0.10 & 0.10 & 0.00 \\
\hline & Slope stabilization $\left(B_{4}\right)$ & 0.20 & 0.30 & 0.25 & 0.25 & 0.00 \\
\hline & Biodiversity $\left(B_{5}\right)$ & 0.10 & 0.10 & 0.35 & 0.40 & 0.05 \\
\hline & Pest control $\left(B_{6}\right)$ & 0.10 & 0.30 & 0.35 & 0.20 & 0.05 \\
\hline & Ecological restoration $\left(B_{7}\right)$ & 0.15 & 0.35 & 0.30 & 0.15 & 0.05 \\
\hline & Runoff collection $\left(B_{8}\right)$ & 0.20 & 0.30 & 0.30 & 0.10 & 0.10 \\
\hline & Water consumption $\left(B_{9}\right)$ & 0.00 & 0.10 & 0.30 & 0.30 & 0.30 \\
\hline & Forest resistance $\left(B_{10}\right)$ & 0.10 & 0.10 & 0.40 & 0.40 & 0.00 \\
\hline \multirow{8}{*}{ Social benefits $\left(A_{2}\right)$} & Mining area greening $\left(B_{11}\right)$ & 0.30 & 0.40 & 0.25 & 0.05 & 0.00 \\
\hline & Environment beautification $\left(B_{12}\right)$ & 0.30 & 0.40 & 0.25 & 0.05 & 0.00 \\
\hline & Wasteland management $\left(B_{13}\right)$ & 0.40 & 0.30 & 0.25 & 0.05 & 0.00 \\
\hline & Revenue increase $\left(B_{14}\right)$ & 0.30 & 0.30 & 0.25 & 0.10 & 0.05 \\
\hline & Forest land increase $\left(B_{15}\right)$ & 0.30 & 0.40 & 0.25 & 0.05 & 0.00 \\
\hline & Timber storage $\left(B_{16}\right)$ & 0.35 & 0.30 & 0.25 & 0.05 & 0.05 \\
\hline & Scientific research $\left(B_{17}\right)$ & 0.05 & 0.25 & 0.35 & 0.30 & 0.05 \\
\hline & Combined benefit $\left(B_{18}\right)$ & 0.10 & 0.25 & 0.35 & 0.30 & 0.00 \\
\hline \multirow{8}{*}{ Economic benefits $\left(A_{3}\right)$} & Timber income $\left(B_{19}\right)$ & 0.10 & 0.30 & 0.35 & 0.20 & 0.05 \\
\hline & Management and protection investment $\left(B_{20}\right)$ & 0.10 & 0.10 & 0.30 & 0.50 & 0.00 \\
\hline & Forest resources $\left(B_{21}\right)$ & 0.15 & 0.45 & 0.30 & 0.05 & 0.05 \\
\hline & Soil fertilization $\left(B_{22}\right)$ & 0.05 & 0.25 & 0.30 & 0.35 & 0.05 \\
\hline & Technology promotion $\left(B_{23}\right)$ & 0.10 & 0.30 & 0.35 & 0.20 & 0.05 \\
\hline & Species cultivation $\left(B_{24}\right)$ & 0.20 & 0.30 & 0.30 & 0.15 & 0.05 \\
\hline & Direct value $\left(B_{25}\right)$ & 0.00 & 0.40 & 0.30 & 0.25 & 0.05 \\
\hline & Indirect value $\left(B_{26}\right)$ & 0.10 & 0.10 & 0.40 & 0.40 & 0.00 \\
\hline
\end{tabular}

Establishment of comprehensive assessment model. The comprehensive benefits (factor set $U$ ) of eucalyptuses' restoration effect on rare earth tailings are constituted by ecological benefits (factor set $U_{1}$ ), social benefits (factor set $U_{2}$ ) and economic benefits(factor set $U_{3}$ ). So the study includes two layers of factor sets.

The first layer of factor sets: $U=\left\{U_{1}\right.$ (Ecological benefits), $U_{2}$ (Social benefits), $U_{3}$ (Economic benefits)\};

The second layer of factor sets:

$U_{1}=\left\{u_{11}\right.$ (Water conservation), $u_{12}\left(\right.$ Erosion prevention), $u_{13}$ (Soil improvement), $u_{14}($ Slope stabilization), $u_{15}$ (Biodiversity), $u_{16}$ (Pest control), $u_{17}$ (Ecological restoration), $u_{18}$ (Runoff collection), $u_{19}$ (Water consumption), $u_{110}$ (Forest resistance) $\}$,

$U_{2}=\left\{u_{21}\right.$ (Mining area greening), $u_{22}$ (Environment beautification), $u_{23}$ (Wasteland management), $u_{24}$ (Revenue increase), $u_{25}$ (Forest land increase), $u_{26}$ (Timber storage), $u_{27}$ (Scientific research), $u_{28}($ Combined benefit $\left.)\right\}$,

$U_{3}=\left\{u_{31}\right.$ (Timber income), $u_{32}$ (Management and protection investment), $u_{33}$ (Forest resources), $u_{34}$ (Soil fertilization), $u_{35}$ (Technology promotion), $u_{36}$ (Species cultivation), $u_{37}$ (Direct value), $u_{38}$ (Indirect value) $\}$. 
In order to assess each factor in $U_{i}=\left\{U_{i 1}, U_{i 2} \ldots U_{i n}\right\}$ individually, fuzzy mappings was defined as follows.

$$
\begin{gathered}
f_{i:} U_{i} \rightarrow P(V) \\
f_{i}\left(u_{i k}\right)=\left(r_{k 1}^{(i)}, r_{k 2}^{(i)}, \mathrm{L} r_{k m}^{(i)}\right) \in F(V)
\end{gathered}
$$

The evaluation matrix is denoted by $R_{i}$. $\left(U_{i}, V, R_{i}\right)$ was regarded as the primary model. The study firstly obtained the weights of first layer factor sets $A_{i}$ in $U_{i}$ through AHP method, and secondly computed the comprehensive assessment $B_{i}$ of the first layer by way of:

$$
B_{i}=A_{i} \cdot R_{i} \in F(V) \quad(i=1,2, \cdots, p)
$$

Pertaining to the single factor $B_{i}$ assessment of the second layer of factors $U=\left\{U_{1}, U_{2} \ldots U_{p}\right\}$, the fuzzy mappings was defined as $f: U \rightarrow F(V), U_{i} \rightarrow f\left(U_{i}\right)=B_{i}$. The evaluation matrix of the second layer thus can be found:

$$
R=\left[\begin{array}{c}
B_{1} \\
B_{2} \\
\mathrm{M} \\
B_{p}
\end{array}\right]=\left[\begin{array}{cccc}
b_{11} & b_{12} & \mathrm{~L} & b_{1 m} \\
b_{21} & b_{22} & \mathrm{~L} & b_{2 m} \\
\mathrm{M} & \mathrm{M} & \mathrm{M} & \mathrm{M} \\
b_{p 1} & b_{p 2} & \mathrm{~L} & b_{p m}
\end{array}\right]
$$

Taking $(U, V, R)$ as the primary model, the weight matrix $A$ corresponding to the factors in $U$ can be derived through AHP. Then the comprehensive assessment matrix $B$ was computed by: $B=A \cdot R \in F(V)$

Ultimately, the weights of both layers of indices were calculated and enumerated below.

The weights of first layer factor sets: $A=\left(A_{1}, A_{2}, A_{3}\right)=(0.42,0.32,0.26)$;

And the weights of second layer factor sets:

$A_{1}=\left(B_{1}, B_{2}, B_{3}, B_{4}, B_{5}, B_{6}, B_{7}, B_{8}, B_{9}, B_{10}\right)=(0.0870,0.0990,0.1595,0.0990,0.0750,0.0980$, 0.0880, 0.0990, 0.0970, 0.0985);

$A_{2}=\left(B_{11}, B_{12}, B_{13}, B_{14}, B_{15}, B_{16}, B_{17}, B_{18}\right)=(0.1245,0.1000,0.1730,0.0590,0.2015,0.0790,0.1630$, $0.1000)$

$A_{3}=\left(B_{19}, B_{20}, B_{21}, B_{22}, B_{23}, B_{24}, B_{25}, B_{26}\right)=(0.0975,0.0965,0.1800,0.0880,0.1415,0.0990,0.1385$, $0.1590)$.

Comprehensive assessment results. In this study, the weights of all the factors were obtained from experts' scoring and AHP. After that, all the comments corresponding to various assessment factors were normalized, which provided the basis for the construction of fuzzy mappings and evaluation matrices.

The comment sets were defined as: $V=\left\{V_{1}\right.$ (Excellent), $V_{2}$ (Good), $V_{3}$ (Average), $V_{4}($ Poor $)$, $V_{5}$ (Inferior) $\}$.

The single factor assessment matrix was expressed as follows:

$$
R^{1}=R_{10 \times 5}^{1}=\left[\begin{array}{lllll}
r_{11} & r_{12} & r_{13} & r_{14} & r_{15} \\
r_{21} & r_{22} & r_{23} & r_{24} & r_{25} \\
r_{31} & r_{32} & r_{33} & r_{34} & r_{35} \\
\mathrm{~L} & \mathrm{~L} & \mathrm{~L} & \mathrm{~L} & \mathrm{~L} \\
r_{101} & r_{102} & r_{103} & r_{104} & r_{105}
\end{array}\right],
$$

$R^{2}=R_{8 \times 5}^{2}, R^{3}=R_{8 \times 5}^{3}$

$B_{1}=A_{1} \cdot R^{1}=(0.1544,0.2370,0.2959,0.2563,0.0564) \rightarrow V_{3}$

$B_{2}=A_{2} \cdot R^{2}=(0.2605,0.3295,0.2763,0.1187,0.0151) \rightarrow V_{2}$

$B_{3}=A_{3} \cdot R^{3}=(0.1007,0.2854,0.3279,0.2489,0.0372) \rightarrow V_{3}$ 
The assessment results indicate that the ecological, social and economic benefits of eucalyptuses' restoration effect on rare earth tailings were judged as Average, Good and Average, respectively.

With the above comprehensive assessment results for the second layer factor sets, the paper evaluated the comprehensive benefits of eucalyptuses' restoration effect on rare earth tailings.

Based on the definition of the comprehensive assessment matrix of first layer factor sets $B=A \times R=$ $A \times\left\{B_{1}, B_{2}, B_{3}\right\}$, and the weight matrix $A=(0.42,0.32,0.26)$, the value of $B$ was obtained:

$$
B=A \cdot R={ }_{(0.42,0.32,0.26)} \cdot\left[\begin{array}{l}
B_{1} \\
B_{2} \\
B_{3}
\end{array}\right]=(0.1744,0.2792,0.2979,0.2104,0.0382) \rightarrow V_{3}
$$

The results revealed that the overall assessment of the restoration effect from 26 indices was Average.

Then $B$ was normalized to be $B=(0.17,0.28,0.30,0.21,0.04)$.

The results showed that the overall assessment trend of the restoration effect was: $17 \%$ for Excellent, $28 \%$ for Good, $30 \%$ for Average, $21 \%$ for Poor and $4 \%$ for Inferior.

\section{Conclusions and Discussions}

Conclusions. Analytic hierarchy process and fuzzy comprehensive evaluation model were utilized for comprehensive benefit calculation of eucalyptuses' restoration of rare earth tailings, from which the following conclusions can be drawn:

(1) Regarding the ecological restoration status of applying eucalyptuses to the rare earth tailings covered area, the evaluation results of the ecological, social and economic benefits were Average, Good, and Average, respectively.

(2) Currently the overall evaluation of eucalyptuses' ecological restoration effect on rare earth tailings was Average.

(3) At present the overall assessment trend of eucalyptuses' ecological restoration effect on rare earth tailings was: $17 \%$ for Excellent, $28 \%$ for Good, $30 \%$ for Average, $21 \%$ for Poor and $4 \%$ for Inferior.

Discussions. The introduction and plantation of eucalyptuses have always been controversial in forestry ecological research field. Debates on this topic mainly focused on the side effects such as, degradation of forest land capability [8], reduction in biodiversity [9], and simplification of community structure $[10,11]$. However, China has its advantages in eucalyptuses' plantation practice. Particularly in those subtropical and tropical regions, the excellent climate provides favorable conditions for the growth of eucalyptuses. In addition, eucalyptuses were always selected for the vegetation restoration of eco-environmentally degraded or eroded areas owing to their fast-growing features, and strong tolerance to barren soil and acid. For example, in south part of Jiangxi Province affected by rare earth tailings, eucalyptuses grew well and played a pioneering role in the vegetation restoration and ecological environment improvement of that area, with a remarkable benefit.

Results of this study showed that the overall benefits of using eucalyptuses for the ecological restoration of rare earth tailing covered areas were Average, which was consistent with the results published in the literature [12]. In the introduction and plantation process of eucalyptuses in subtropical zones, eucalyptuses presented satisfying growing adaptability and promoted the local vegetation coverage percentage, which proved their social and ecological returns. But problems also turned up in the assessment of the ecological benefits. These problems mainly include the simplification of biodiversity, the high demand for fertilization, and serious water deficiency. All these problems have emerged in the current practice. Hence, the scientific ecological restoration of rare earth tailings requires reasonable arrangement for the introduction and plantation of eucalyptuses, and selection of other plant species suitable for rare earth tailing covered land to grow together with eucalyptuses, in addition to the existing restoration measures. These methods can help enrich the biodiversity, improve 
soil quality, and regain land capacity. Only in this way can the ecological restoration be optimized, at the same time the soil erosion be controlled, and the ecological environment of the studied area be enhanced.

\section{Acknowledgements}

This research was financially supported by the Foundation of Key Laboratory of Soil Erosion and Control of Jiangxi Province, China (JXSB201202), The innovation experiment program for university students of Jiangxi Province, China (201311319003) and the Water Science and Technology Planning Project of Jiangxi Province, China(KT201540).

\section{References}

[1] Huaxi Qiu, Gang Pan and Zefeng Xu. "Southern Desert" into "treasure" [N]. Chinese Mining Newspaper, 2015-12-8(4)

[2] Dunfu Song, Xiaojin Zhang, Xin Peng and Honglan Huang. Journal of China Hydrology, 35(3) (2015),p.31-37(In Chinese)

[3] Guoqin Huang and Qiguo Zhao. Acta Ecologica Sinica, 34(18)(2014),p.5142-5152(In Chinese)

[4] Chengbiao Huang. Eucalypt Science and Technology, 29(3)(2012),p.44-47(In Chinese)

[5] Fuke Yu, Xinhui Huang, Keqin Wang and Changqun Duan. Chinese Journal of Eco-Agriculture, 17(2)(2009),p.393-398(In Chinese)

[6] Deyi Feng, Shibo Lou and Mingzhou Lin. Application of Fuzzy math (Earthquake press, Beijing China. 1988, p.74-75) (In Chinese)

[7] Suofa Zhuang. Journal of Hefei University of technology. 23(4)(2000),p.582-585,590(In Chinese)

[8] Shaoxiong Chen. Tropical forestry, 33(4)(2005),p.26-30(In Chinese)

[9] Qionghui Wu and Hao Zhang. The science and technology of forestry in Guangdong, 22(3)(2006),p.133-136(In Chinese)

[10] Hua Qin.Study on the structure characteristics of Eucalyptus Plantation and its influence on the ecological environment in Yunnan Province (The master thesis of Kunming University of science and technology, China. 2007) (In Chinese)

[11] Angang Ming. Study on the complexity of community structure and the change of soil nutrient in the continuous planting Eucalypt plantations(The master thesis of Guangxi University, China. 2008) (In Chinese)

[12] Hua Liu and Jianhua Li. Ecology and environmental sciences, 18(6)(2009),p.2237-2242(In Chinese) 